\title{
Việc áp dụng các nguyên tắc cơ bản của pháp luật quốc tế trong vụ giải quyết tranh chấp chủ quyền đảo Pedra Branca và bài học kinh nghiệm cho Việt Nam
}

\author{
Đào Thị Thu Hường * \\ Khoa Luật, Đại học Quốc gia Hà Nội, 144 Xuân Thủy, Cà̀u Giấy, Hà Nội, Việt Nam \\ Nhận ngày 16 tháng 8 năm 2017 \\ Chỉnh sửa ngày 20 tháng 9 năm 2017; Chấp nhận đăng ngày 25 tháng 9 năm 2017
}

\begin{abstract}
Tóm tắt: Các nguyên tắc cơ bản của pháp luật quốc tế có vai trò rất quan trọng trong việc giải quyết các tranh chấp quốc tế nói chung và giải quyết các tranh chấp về quốc tế về biển, đảo nói riêng, góp phần bảo vệ hòa bình, an ninh quốc tế. Trên cơ sở tập trung nghiên cứu toàn bộ quá trình giải quyết tranh chấp giữa Singapore và Malaysia về chủ quyền đối với Pedra Branca và các đá dưới góc độ các nguyên tắc cơ bản của pháp luật quốc tế, bài viết sẽ đưa ra đánh giá về việc tôn trọng, tuân thủ pháp luật quốc tế của các chủ thể liên quan và bài học kinh nghiệm cho Việt Nam trong việc giải quyêt các tranh chấp tại Biển Đông.
\end{abstract}

Tù khóa: Tranh chấp chủ quyền Pedra Branca, Tòa án công lý quốc tế, nguyên tắc cơ bản của pháp luật quốc tế, vụ tranh chấp Malaysia và Singapore.

Các nguyên tắc cơ bản của luật quốc tế là những tư tưởng chính trị, pháp lý mang tính chỉ đạo, nền tảng, bao trùm và có giá trị bắt buộc chung (Jus cogens) đối với mọi chủ thể của luật quốc tế áp dụng trong mọi điều kiện, hoàn cảnh, lĩnh vực của quan hệ quốc tế $[1$, tr.71]. Các nguyên tắc này được ghi nhận rộng rãi trong nhiều văn kiện pháp lý quốc tế song phương, đa phương, khu vực hoặc toàn cầu trong đó, Hiến chương LHQ năm 1945, Tuyên bố ngày 24/10/1970 của Đại hội đồng LHQ về các nguyên tắc cơ bản của luật quốc tế điều chỉnh mối quan hệ hữu nghị, hợp tác giữa các quốc gia phù hợp với Hiến chương LHQ được coi là những văn kiện điển hình có tính chất pháp lý

\footnotetext{
•ĐT.: 84-24-37548514.

Email: yellow_rose1973@yahoo.com.vn

https://doi.org/10.25073/2588-1167/vnuls.4080
}

và tầm ảnh hưởng rộng lớn đối với hành vi xử sự của các chủ thể luật quốc tế khi tham gia vào các quan hệ quốc tế. Theo các văn kiện này, các nguyên tắc cơ bản bao gồm: nguyên tắc cấm sử dụng vũ lực và đe dọa sử dụng vũ lực, nguyên tắc giải quyết các tranh chấp quốc tế bằng các biện pháp hòa bình, nguyên tắc không can thiệp vào công việc nội bộ của quốc gia khác, nguyên tắc các quốc gia có nghĩa vụ hợp tác, nguyên tắc về quyền bình đẳng và tự quyết của các dân tộc, nguyên tắc bình đẳng về chủ quyền giữa các quốc gia và nguyên tắc tận tâm, thiện chí thực hiện cam kết quốc tế. Các nguyên tắc cơ bản của pháp luật quốc tế là cơ sở để duy trì trật tự pháp lý quốc tế, kim chỉ nam cho việc giải quyết các tranh chấp quốc tế trong đó có việc giải quyết các tranh chấp quốc tế về biển, đảo, góp phần bảo vệ hòa bình an ninh quốc tế. Đặc biệt, trong vụ tranh chấp chủ quyền đối với 
Pedra Branca, Middle Rocks và South Ledge giữa Singapore và Malaysia, các nguyên tắc này đã được áp dụng trực tiếp và có ý nghĩa vô cùng quan trọng trong toàn bộ quá trình giải quyết tranh chấp.

\section{Khái quát vụ tranh chấp}

Pedra Branca - theo cách gọi của Singapore hoặc Pulau Batu Puteh - theo cách gọi của Malaysia đều có nghĩa là Đá Trắng (sau đây gọi chung là Pedra Branca) là đảo đá nhỏ, dài $137 \mathrm{~m}$, rộng $60 \mathrm{~m}$, có diện tích khoảng $8560 \mathrm{~m}^{2}$ khi thủy triều xuống. Về vị trí địa lý, Pedra Branca nằm ở tọa độ $1^{\circ} 19^{\prime} 48^{\prime \prime} \mathrm{N}, 104^{\circ}$ 24'27" E; khoảng 24 hải lý về phía Đông của eo biển Singapore, 7,7 hải lý về phía Nam của bang Johor của Malaysia, và 7,6 hải lý phía Bắc của Bintan của Indonesia [2, đoạn 16, 17]. Sau quá trình 3 năm chuẩn bị, ngọn hải đăng Horsburgh trên đảo Pedra Branca được người Anh xây dựng từ năm 1847 đến năm 1851 và chuyển giao cho Singapore (lúc đó là thuộc địa của Anh theo Hiệp ước Anglo-Dutch năm 1824) [2, đoạn 16]. Middle Rocks bao gồm hai cụm đá nhỏ rộng khoảng $250 \mathrm{~m}$, cao từ 0,6 đến $1,2 \mathrm{~m}$ và nằm trên mặt nước khi thủy triều lên cao, nằm cách 0,6 hải lý về phía nam của Pedra Branca. South Ledge là một khối đá chỉ có thể nhìn thấy khi thủy triều xuống, nằm 1,7 hải lý về phía nam Middle Rocks và 2,2 hải lý về phía nam-tây nam của Pedra Branca [2, đoạn 18]. Cả ba cấu trúc địa lý trên đều nằm ở lối vào phía Đông của eo biển Singapore, gần cửa ngõ vào Biển Đông, về phía Đông của Middle Channel, thuộc khu vực các tuyến đường biển nhộn nhịp nhất trên thế giới [3].

Tranh chấp xảy ra vào năm 1979 , sau khi Malaysia đưa ra yêu sách chính thức đối với đảo Pedra Branca thông qua việc xuất bản hai tấm bản đồ của quốc gia về "Ranh giới Lãnh hải và Thềm lục địa của Malaysia", ngày 14/2/1980 Singapore đã đưa ra thông cáo phản đối bản đồ và lập luận của Malaysia [2]. Singapore khẳng định đã sở hữu và thực thi chủ quyền hòa bình và hữu hiệu đối với hòn đảo này hơn 150 năm, trong đó có việc quản lý và tiến hành xây dựng nhiều công trình quan trọng trên đảo mà Malaysia không có bất kỳ động thái hoặc phản hồi nào. Kéo dài suốt thập kỷ 80 , tranh chấp về chủ quyền Pedra Branca đã tác động đến quan hệ song phương giữa Singapore và Malaysia và là chủ đề được thảo luận ở nhiều cấp và được cả người dân lẫn báo giới hai nước quan tâm theo dõi [4, tr.20-34]. Tranh chấp này chỉ chấm dứt sau khi ICJ chính thức đưa ra phán quyết giải quyết vụ việc ngày 23/5/2008.

Trên cơ sở tập trung nghiên cứu toàn bộ quá trình giải quyết tranh chấp chủ quyền trên biển này dưới góc độ các nguyên tắc cơ bản của pháp luật quốc tế, bài viết sẽ đưa ra đánh giá về việc tôn trọng, tuân thủ pháp luật quốc tế của các chủ thể liên quan và bài học kinh nghiệm cho Việt Nam trong việc giải quyết các tranh chấp tại Biển Đông.

\section{Nguyên tắc cấm sử dụng vũ lực và đe dọa sử dụng vũ lực và nguyên tắc giải quyết tranh chấp quốc tế bằng các biện pháp hòa bình}

Đây là những nguyên tắc cơ bản của pháp luật quốc tế, theo đó, các quốc gia không được sử dụng vũ lực hoặc đe dọa sử dụng vũ lực như là các biện pháp giải quyết các tranh chấp quốc tế nói chung, các tranh chấp quốc tế về biển, đảo nói riêng; sự tồn tại của một tranh chấp cũng như sự thất bại của một thủ tục hòa bình giải quyết tranh chấp sẽ không cho phép việc đe dọa hay sử dụng vũ lực của bất kỳ quốc gia nào; đồng thời, các bên tranh chấp phải có nghĩa vụ giải quyết các mâu thuẫn, xung đột có liên quan bằng các biện pháp hòa bình, không phương hại đến hòa bình, an ninh quốc tế, công bằng và công lý, phải sớm tìm kiếm các biện pháp hòa bình để giải quyết các tranh chấp phát sinh, phải từ bỏ bất kỳ hành vi nào có thể làm trầm trọng thêm tình hình hiện tại và gây nguy hiểm cho việc giữ gìn hòa bình và an ninh quốc tế $[5,6]$.

Trong vụ Pedra Branca, ngay từ khi tranh chấp phát sinh, tình hình trên vùng biển quanh các đảo, đá tranh chấp trở nên căng thẳng. 
Malaysia, từ năm 1989, đã nhiều lần cho các tàu có vũ trang đi vào sát đảo Pedra Branca, thậm chí còn thả neo trong vùng lãnh hải của Singapore. Chỉ riêng trong khoảng thời gian từ năm 2000 đến 2008, đã có 568 vụ tàu Malaysia xâm nhập vào lãnh hải đảo Pedra Branca. Tuy vậy, Singapore đã chỉ thị cho Hải quân tránh va chạm, không để cho tình hình vượt ngoài tầm kiểm soát và không để tranh chấp bùng nổ thành xung đột bạo lực [7, tr.164-186], đồng thời tiến hành các biện pháp ngoại giao để giảm căng thẳng. Bộ Ngoại giao Singapore và cả Cao uỷ của Singapore tại Kuala Lumpur đã nhiều lần gửi công hàm cho Bộ Ngoại giao Malaysia đề nghị tàu hải quân Malaysia chấm dứt hành động xâm nhập vào vùng biển của mình và bày tỏ nguyện vọng hai bên cùng tìm kiếm giải pháp hoà bình cho tranh chấp. Có thể nói, Singapore đã thực hiện nghiêm túc nghĩa vụ kiềm chế xung đột và thiện chí của Singapore trong việc tìm kiếm giải pháp chính là một trong những cơ sở quan trọng cho việc giải quyết tranh chấp này bằng biện pháp hòa bình.

Đàm phán là một biện pháp rất quan trọng để kiềm chế và quản lý tranh chấp, không để tranh chấp bùng nổ thành xung đột bạo lực. Các cuộc tiếp xúc và thương lượng song phương hoặc bên lề các hội nghị quốc tế của Bộ trưởng Ngoại giao và Thủ tướng của cả hai nước đã thúc đầy tranh chấp đi theo chiều hướng giải quyết hoà bình. Việc thống nhất ký kết Thỏa thuận đặc biệt ngày 09/05/2003 đồng ý đưa vụ tranh chấp ra giải quyết tại Tòa án Công lý quốc tế (ICJ) chính là kết quả của sự hành xử văn minh giữa hai quốc gia Đông Nam Á này. Cụ thể:

Nhận thức được vai trò của luật pháp quốc tế, đặc biệt là đối với các nước nhỏ trong quan hệ với các nước lớn hơn, ngay từ năm 1989 Singapore đã chủ động đề xuất giải quyết tranh chấp Pedra Branca với Malaysia bằng pháp luật quốc tế thông qua ICJ và kiên trì đề xuất này cho đến khi nhận được sự đồng ý của Malaysia. Bên lề Hội nghị các nhà Lãnh đạo Chính phủ Khối thịnh vượng chung (16/10/1991) tại Harare, Zimbabwe, thủ tướng hai nước đã thống nhất nếu có tài liệu nêu lên hòn đảo thuộc về bên kia, cả hai bên sẽ chấp nhận hiện trạng đó. Thoả thuận này đã định hướng cho toàn bộ tiến trình giải quyết tranh chấp sau này.

Ngày 22/1/1992, tại một cuộc họp bên lề Cấp cao ASEAN lần thứ 4 , Thủ tướng hai nước quyết định sẽ tổ chức trao đổi tài liệu pháp lý và đàm phán để giải quyết tranh chấp trên cơ sở các nguyên tắc cơ bản của luật pháp quốc tế [4, tr.20-34]. Trong Công hàm ngày 17/2/1992 và các tài liệu liên quan Singapore trao cho Malaysia có đề cập đến khả năng giải quyết tranh chấp thông qua ICJ nếu đàm phán không thành công. Tuy nhiên, khả năng giải quyết tranh chấp bởi cơ quan tài phán này không được phản hồi trong Công hàm và tài liệu liên quan mà Malaysia gửi cho Singapore ngày 29/6/1992.

Qua hai vòng đàm phán trong hai năm 1993 và 1994 để trao đổi các tài liệu lịch sử và pháp lý nhằm xác định chủ quyền đối với Pedra Branca, Singapore chính thức đề nghị đưa Middle Rocks và South Ledge vào phạm vi khu vực tranh chấp; đồng thời sau khi vòng đàm phán thứ hai không có kết quả, Malaysia đã bày tỏ sự chấp nhận xem xét khả năng giải quyết tranh chấp bằng biện pháp tài phán quốc tế. Ngày 6/9/1994 Thủ tướng hai nước tuyên bố hai bên đã đồng ý về nguyên tắc đưa tranh chấp chủ quyền đối với đảo Pedra Branca ra giải quyết bởi một "bên thứ ba" nhưng không chính thức xác định là cơ quan tài phán nào và giao cho chuyên gia pháp lý hai nước nghiên cứu tìm cơ chế giải quyêt tranh chấp phù hợp.

Năm 1998, kết thúc quá trình đàm phán đầy khó khăn, hai bên đã xác định được phạm vi điều chỉnh của Thỏa thuận và thống nhất không yêu cầu Tòa xác định quyền và lợi ích của bên không có chủ quyền đối với Pedra Branca [4]. Thỏa thuận đặc biệt đã được hai bên ký ngày $6 / 2 / 2003$ và phê chuẩn vào ngày 9/5/2003. Ngày 24/7/2003, Ngoại trưởng hai nước ký Thông báo chung gửi ICJ, chính thức trao cho ICJ quyền phân định chủ quyền đối với Pedra Branca, Middle Rocks và South Ledge [8]. 
Có thể thấy, sau hơn hai mươi năm từ thời điểm phát sinh tranh chấp, với thiện chí và quyết tâm chính trị rất cao (mà đặc biệt là Singapore), các bên đã kiên trì đàm phán và chính thức tìm được tiếng nói chung, thống nhất lựa chọn được phương thức và biện pháp cụ thể cho việc giải quyết tranh chấp. Thỏa thuận giải quyết tranh chấp tại ICJ là quyết sách đúng đắn của cả Singapore và Malaysia, thể hiện sự tuân thủ và áp dụng một cách nghiêm túc, triệt để các nguyên tắc cơ bản của pháp luật quốc tế trong việc kiên trì thực hiện nghĩa vụ tìm kiếm phương thức giải quyết tranh chấp phù hợp, kiềm chế, quản lý tranh chấp không làm phức tạp thêm tình hình trong quá trình giải quyết tranh chấp, loại bỏ được nguy cơ sử dụng vũ lực gây ảnh hưởng đến an ninh, hòa bình khu vực.

\section{Nguyên tắc bình đẳng về chủ quyền giữa các quốc gia và nguyên tắc không can thiệp vào công việc nội bộ của quốc gia khác}

Là nguyên tắc quan trọng của pháp luật quốc tế, bình đẳng về chủ quyền giữa các quốc gia và không can thiệp vào công việc nội bộ của quốc gia khác chính là sự thể hiện quyền bình đẳng, tự quyết của quốc gia trong tất cả các công việc đối nội và đối ngoại mà không bị chi phối, áp đặt từ chủ thể khác trên cơ sở tôn trọng chủ quyền của các quốc gia khác trong cộng đồng quốc tế. Qua thực tiễn giải quyết vụ tranh chấp Pedra Branca, chúng ta có thể khẳng định các nguyên tắc này đã được vận dụng và tôn trọng bởi cả hai bên Singapore và Malaysia và cơ quan tài phán ICJ, cụ thể trên các phương diện cơ bản sau:

Thư nhất, các bên trong tranh chấp đều bình đẳng với nhau trong việc chủ động chọn hướng giải quyết tranh chấp phù hợp với bản chất của tranh chấp và pháp luật quốc tế; chủ động lựa chọn việc áp dụng biện pháp pháp lý, giải quyết tranh chấp tại một cơ quan tài phán quốc tế làm cơ sở đề nghị với bên kia khi biện pháp đàm phán thương lượng không đạt được kêt quả, cũng như bình đẳng trong việc thỏa thuận lựa chọn cơ quan tài phán quốc tế. Malaysia và
Singapore đã cùng thống nhất chọn hướng giải quyết tranh chấp đảo Pedra Branca và các đá trên cơ sở pháp lý thông qua việc ký kết Thỏa thuận đặc biệt ngày 09/05/2003 đồng ý đưa vụ tranh chấp ra giải quyết tại ICJ. Sự lựa chọn này là nhân tố quan trọng đưa đến một giải pháp cuối cùng cho tranh chấp, đồng thời vẫn giữ được quan hệ chính trị tốt đẹp giữa hai quốc gia. Sự kiện Malaysia chỉ chấp nhận ký Thỏa thuận với Singapore sau khi ICJ ra phán quyết vào ngày 17/12/2002 tuyên bố Pulau Ligitan và Pulau Sipadan thuộc về Malaysia trong vụ tranh chấp giữa Indonesia v. Malaysia cho thấy Malaysia đã cân nhắc rất kỹ lưỡng và sử dụng quyền của quốc gia trong vấn đề quyết định lựa chọn phương thức và cơ quan tài phán giải quyết tranh chấp của mình phù hợp với pháp luật quốc tế.

Thú hai, trong suốt quá trình giải quyết tranh chấp, với vai trò người phân xử, cơ quan tài phán ICJ đã rất tôn trọng và đảm bảo quyền lợi của các trên cơ sở tôn trọng nguyên tắc bình đẳng về chủ quyền của các quốc gia; đồng thời, cả Singapore và Malaysia cũng đều hoàn toàn chủ động và bình đẳng về vị thế, khai thác sử dụng triệt để các quyền và nghĩa vụ chứng minh trong suốt quá trình tố tụng để bảo vệ quyền lợi của mình thông qua việc thể hiện yêu sách, cung cấp chứng cứ pháp lý, lập luận bảo vệ yêu sách của mình; đòi hỏi bên kia đưa ra chứng cứ chứng minh và chất vấn tính chính xác của chứng cứ, phản biện các lập luận, chứng cứ của bên kia...

Malaysia đưa ra quan điểm để khẳng định mình đã đặt chủ quyền ban đầu đối với Pedra Branca trong một khoảng thời gian dài: nước tiền nhiệm của Malaysia - Vương quốc Johor đã có danh nghĩa chủ quyền trên đảo Pedra Branca, đã duy trì danh nghĩa này cho đến những năm 1840. Malaysia lập luận Vương quốc Johor bao gồm tất cả các đảo trong một vùng rộng lớn, gồm các đảo trong eo biển Singapore, như Pulau Batu Puteth và các đảo ở phía bắc và phía nam eo biển, tức bao gồm luôn Singapore và các đảo kế cận. Một thực tế chỉ ra rằng Pulau $B a t u$ Puteth nằm ở lối vào phía đông của eo biển Singapore và nằm ngay giữa Vương 
quốc Hồi giáo cũ của Johor. Malaysia khẳng định từ khi Vương quốc Johor thành lập, đảo Pulau Batu Puteth luôn là một phần lãnh thổ của Vương quốc Johor và chưa bao giờ, ở bất kỳ một thời điểm nào, đảo là một vùng đất vô chủ để có thể dựa vào đó mà chiếm hữu[2, đoạn 47,48]. Vì vậy, Pedra Branca luôn luôn là một phần của Nhà nước Johor của người Malaysia, không gì có thể xảy ra để thay thế chủ quyền của Malaysia đối với đảo; sự hiện diện của Singapore trên đảo với mục đích duy nhất là xây dựng và duy trì một ngọn hải đăng ở đó (với sự cho phép của chủ quyền lãnh thổ) là không thể được trao quyền đối với đảo. Không có bằng chứng nào chứng minh Johor đã đánh mất chủ quyền hay Johor có ý định nhượng lại, từ bỏ chủ quyền đối với hòn đảo này $[2$, đoạn 37,38]. Trên thực tế, cùng với việc cho rằng cung cấp bằng chứng để chứng minh là phận sự của bên cáo buộc, Malaysia đã quá chú trọng vai trò của danh nghĩa lịch sử nên ít quan tâm đến nguyên tắc chiếm hữu thực sự và thực thi chủ quyền thực sự, hiệu quả và hoà bình là nguyên tắc chủ yếu được các thẩm phán ICJ dựa vào để đưa ra phán quyết cuối cùng cho những tranh chấp chủ quyền biển, đảo trong những thập kỷ vừa qua. Tuy nhiên, theo một nguyên tắc chung của pháp luật, được xác định bởi Tòa, bên nào đưa ra một yểu tố nhằm hỗ trợ cho đòi hỏi của mình phải có bổn phận chứng minh điều đó. Nghĩa là, phía Malaysia phải có bổn phận chứng minh danh nghĩa chủ quyền của họ tại Pedra Branca trước thời kỳ 18471851, đồng thời phía Singapore phải chứng minh đảo này là vô chủ[ $[9$, tr.402]. Theo hướng chiến lược này, các bản tranh tụng của Malaysia trước Toà án chủ yếu khẳng định danh nghĩa ban đầu của Malaysia đối với đảo Pedra Branca và bác bỏ chủ quyền của Singapore, mà không nêu được những chứng cứ thực thi chủ quyền đối với hòn đảo này. Cũng có thể người Malaysia đã thấy được điểm yếu trong lập luận của mình do thiếu cơ sở pháp lý để khẳng định chủ quyền nên họ nhấn mạnh đến các bằng chứng lịch sử [9, tr.443].

Về phía Singapore, để bảo vệ quyền lợi, Singapore cũng thể hiện lập truờng quan điềm của mình về chủ quyền của Singapore đối với Pedra Branca trong bản Bị vong lục và tranh luận tại Tòa dựa trên việc chiếm hữu hợp pháp hòn đảo của chính quyền Anh tại Singapore trong giai đoạn từ năm 1847 đến năm 1851 và sau đó là tiếp tục duy trì, thực hiện quyền lực nhà nước đối với Pedra Branca của Singapore [2, đoạn 39].

Để bảo vệ quan điểm của mình, Singapore đã triệt để vận dụng quyền đòi hỏi bên tranh chấp kia đưa ra chứng cú và chất vấn tính xác thưc của chưng cú, yêu cầu Malaysia phải cung cấp nhũng chứng cú cu thể để chứng minh Công quốc Johor cũ có chủ quyền trên đảo Pedra Branca và có các hành vi mang tính thực thi chủ quyền đối với hòn đảo này. Đồng thời, tại các phiên tranh tụng ở Toà, Singapore đã đưa ra những chứng cứ xác thực có giá trị thuyết phục cao để chứng minh Công quốc Johor không coi đảo Pedra Branca là lãnh thổ của mình, trong đó quan trọng nhất là bức thư ngày 21/9/1953 của Quyền Bộ trưởng Ngoại giao Johor gửi Bộ trưởng Thuộc địa ở Singapore và những tấm bản đồ do Malaysia đã phát hành chính thức vào các năm 1962, 1965 , 1974 và 1975 , coi đó là chứng cứ xác thực để chứng minh rằng Malaysia đã thừa nhận chủ quyền của Singapore đối với hòn đảo này; Singapore cũng cung cấp tu liệu để chíng minh ngược lại những tài liệu do Malaysia sử dụng để lập luận trước Toà là người Anh đã phải xin phép Vương quốc Johor để xây ngọn hải đăng Horsburgh trên đảo Pedra Branca vào năm 1850 chỉ liên quan đến hòn đảo khác, đảo Peak Rock, mà không phải là đảo Pedra Branca và người Anh đã không xin phép Malaysia để xây ngọn hải đăng bởi vì họ không cho rằng hòn đảo này thuộc về Malaysia[2]. Những tư liệu trên của Singapore đã làm lung lay cơ sở pháp lý và những lập luận của đối phương, là một trong những chứng cứ quan trọng góp phần làm cho các thẩm phán $\mathrm{ICJ}$ tin rằng từ lâu đảo Pedra Branca không thuộc về Malaysia.

Bên cạnh việc xây dựng những lập luận pháp lý trên cơ sở những chứng cứ xác thực để khẳng định chủ quyền, Singapore đã tiến hành phản biện một cách hiệu quả các lập luận và 
chứng cứ của đối phương $[9$, tr.443]. Khi Malaysia chứng minh đảo Pedra Branca thuộc chủ quyền của Công quốc Johor vào thời điểm ngọn hải đăng đầu tiên được xây dựng tại đảo này vào năm 1850 và lập luận trong suốt hơn 150 năm Chính phủ Anh và Singapore không thực thi chủ quyền trên đảo Pedra Branca mà chỉ đơn thuần là vận hành ngọn hải đăng vì mục đích bảo đảm an toàn hàng hải, thì Singapore đã chứng minh một cách thuyết phục trước Toà rằng Chính phủ Anh đã thụ đắc hòn đảo vào năm 1847. Chính phủ Anh và sau đó là Chính phủ Singapore (quốc gia thừa kế của Anh) đã thực hiện đầy đủ các hành vi chủ quyền và quyền tài phán trên hòn đảo và các vùng biển xung quanh nó như đưa ra thông báo với các tàu thuyền; thường xuyên bảo trì và mở rộng các thiết bị trên đảo, đề xuất kế hoạch cải tạo mở rộng đảo, thu tập dữ liệu thời tiết, dựng cờ hiệu; các cuộc viếng thăm của các quan chức cấp cao Singapore, kiểm soát việc đến và rời đảo của người nước ngoài, trong đó có công dân Malaysia, cấp giấy phép cho các bên thứ ba thực hiện các hoạt động nghiên cứu, khảo sát vùng biển xung quanh và trục vớt tàu thuyền, thực thi quyền tài phán để điều tra các vụ đắm tàu diễn ra trong vùng biển quanh Pedra Branca...

Trên cơ sở xem xét vấn đề tình trạng pháp lý của Pedra Branca trước và sau những năm 1844 thông qua lập luận, chứng cứ của các bên, ICJ đã bác lập luận của Singapore cho rằng trước năm 1844 Pedra Brance là lãnh thổ vô chủ (terra nullius) và kết luận vào thời điểm này, đảo Pedra Branca/Pulau Batu Puteth thuộc chủ quyền của Vương quốc Johor - nước tiền nhiệm của Malaysia. Tuy nhiên, Tòa cũng ghi nhận, từ những năm 1840 đến thời điểm phát sinh tranh chấp, năm 1980, chủ quyền đối với Pedra Branca đã được chuyển cho Singapore qua các hoạt động thực hiện chủ quyền liên tục và hòa bình của Anh (và sau đó là Singapore) trong một thời gian dài mà Malaysia không có bất kỳ sự phản đối nào. Đồng thời Toà nhận định, trong một số tình huống cụ thể, Malaysia thậm chí còn ngầm thừa nhận việc thực hiện chủ quyền của Singapore mà bức thư năm 1953 được Tòa xem như một trong những bằng chứng cho thấy Malaysia không tuyên bố chủ quyền đối với Pedra Branca [2, đoạn 273-277].

Tòa kết luận chủ quyền đối với Middle Rocks vẫn thuộc về Malaysia [2, đoạn 288-290] trên cơ sở bác lập luận của Singapore (cho rằng Middle Rocks là một phần của nhóm đảo Pedra Branca) và nhận định Middle Rocks không phải là lãnh thổ vô chủ mà thuộc chủ quyền của Johor trước năm 1844, các hoạt động xác lập chủ quyền của Anh và Singapore sau năm 1844 chỉ được tiến hành đối với Pedra Branca và không áp dụng đối với Middle Rocks. Đồng thời đối với South Ledge, do bản chất là bãi cạn theo Điều 13 UNCLOS và trên thực tế South Ledge nằm trong vùng lãnh hải chồng lấn được tạo bởi phần đất liền của Malaysia và các đảo Pedra Branca và Middle Rocks. Do không có thẩm quyền phân định đường ranh giới lãnh hải trong khu vực, nên ICJ chỉ phán quyết rằng, nếu đảo này nằm trong vùng nước lãnh hải được tạo bởi đảo Pedra Branca thì sẽ thuộc chủ quyền của Singapore, ngược lại nếu nó nằm trong vùng nước lãnh hải được tạo bởi đảo Middle Rocks thì sẽ thuộc chủ quyền của Malaysia [2, đoạn 299].

\section{Nguyên tắc các quốc gia có nghĩa vụ hợp tác và nguyên tắc tận tâm, thiện chí thực hiện cam kết quốc tế}

Các quốc gia có nghĩa vụ hợp tác thực sự là một nguyên tắc có mối quan hệ chặt chẽ với nguyên tắc hòa bình giải quyết các tranh chấp quốc tế, biểu hiện trực tiếp ở việc các quốc gia có nghĩa vụ hợp tác với nhau để cùng tìm kiếm các giải pháp hiệu quả trong việc giải quyết tranh chấp ngay từ khi tranh chấp phát sinh, cùng nhau quản lý, kiểm soát tranh chấp, không thực hiện những hành vi làm leo thang tranh chấp, đồng thời hợp tác với nhau trong việc giải quyết các vấn đề phát sinh trong quá trình giải quyết tranh chấp. Có thể nhận định, nguyên tắc này trong thực tiễn giải quyết tranh chấp Pedra Branca đã được Singapore và Malaysia tôn trọng và áp dụng một cách tương đối toàn diện, đặc biệt với vai trò của Singapore: kiên trì đàm 
phán hợp tác tích cực với Malaysia trong việc giải quyết tranh chấp suốt hơn hai mươi năm nhằm đạt được Thỏa thuận về việc lựa chọn giải pháp và hợp tác trong suốt quá trình tố tụng tại ICJ để có được kết quả phân xử cuối cùng. Điều này đã góp phần quan trọng trong việc xây dựng củng cố lòng tin, tăng cường quan hệ hữu nghị giữa các bên, góp phần duy trì hòa bình, an ninh trong khu vực và quốc tế.

Phán quyết giải quyết tranh chấp của ICJ ngày 23/5/2008 đã được quốc gia hai bên liên quan đón nhận một cách thuận lợi, không nước nào phản đối kết quả phân xử. Bộ trưởng Ngoại giao Malaysia Rais Yatim mô tả quyết định của ICJ là giải pháp cả hai cùng thắng và sẽ tác động tích cực đến quan hệ song phương giữa hai nước. Phó Thủ tướng Najib Tun Razak cho rằng phán quyết là một quyết định cân bằng vì Malaysia cũng đã thành công một phần trong yêu sách lãnh thổ của mình. Phó thủ tướng Singapore $\mathrm{S}$. Jayakumar bày tỏ sự hài lòng của Singapore vì Tòa đã trao chủ quyền của Pedra Branca, đối tượng chính của cuộc tranh cãi, cho Singapore. Thủ tướng Lý Hiển Long nhấn mạnh việc đưa tranh chấp lên Tòa phân xử là một cách tốt để các bên có thể giải quyết những bất đồng mà vẫn duy trì quan hệ láng giềng tốt đẹp [10].

Mặc dù cũng có một số phản ứng chính trị nội bộ về kết quả phán quyết, cả Malaysia và Singapore đều khẳng định cam kết tuân thủ và thưcc hiện đầy đủ phán quyết của ICJ. Ngày 03/6/2008, Malaysia và Singapore đã thống nhất thành lập Üy ban Kỹ thuật chung Malaysia - Singapore (MSJTC) để triển khai thực hiện phán quyết. Malaysia và Singapore cũng nhất trí một trong hai bên đều có thể hỗ trợ tàu gặp nạn tại các vùng biển gần Pedra Branca, Middle Rocks và South Ledge và ngư dân cả hai nước đều có thể tiếp tục các hoạt động đánh bắt cá truyền thống của họ tại vùng biển này[11]. Như vậy, trao thẩm quyền xét xử cho ICJ, tôn trọng và tuân thủ theo nội dung của phán quyết đã thể hiện sự tận tâm thiện chí của các bên, phù hợp với nguyên tắc cơ bản của pháp luật quốc tế. Phán quyết của Toà về vụ việc này đã khép lại cuộc tranh chấp kéo dài gần ba thập kỷ, đồng thời giúp duy trì và thúc đẩy mối quan hệ giữa Malaysia và Singapore, duy trì hòa bình, an ninh quốc tế.

Tuy nhiên, đến năm 2013, MSJTC rơi vào tình trạng bế tắc do hai bên không thể nhất trí về lãnh hải quanh Pedra Branca và South Ledge. Tình trạng bất định kéo dài này đã gây khó khăn cho nhiệm vụ đảm bảo mối quan hệ hòa bình và hữu nghị giữa hai nước. Gần 9 năm sau, ngày $2 / 2 / 2017$, Malaysia đã áp dụng Điều 61 Quy chế Tòa án quốc tế, gửi đơn yêu cầu ICJ sửa đổi phán quyết 2008 về chủ quyền đối với Pedra Branca với lý do có những tình tiết mới được phát hiện mà tính chất của chúng có thể ảnh hưởng đến quyết định và khi phán quyết được đưa ra, cả tòa án và bên yêu cầu xem xét lại đều không biết tới [12, Điều 61]. Malaysia đã viện dẫn 3 tài liệu được Anh giải mật gần đây để hỗ trợ cho việc nộp đơn yêu cầu xem xét lại phán quyết về Pedra Branca, đó là thư từ trao đổi nội bộ của giới chức Singapore thời thuộc địa năm 1958, báo cáo tai nạn của Hải quân Anh năm 1958 và một bản đồ chú thích về các hoạt động hải quân từ thập niên 1960. Những tài liệu này đã được tìm thấy trong $\mathrm{Co}$ quan Lưu trữ quốc gia Anh từ ngày 4/8/2016 đến ngày 30/1/2017 [13]. Tháng 6 năm 2017, Malaysia tiếp tục nộp đơn xin giải thích nhằm làm rõ phán quyết phán quyết năm 2008 của ICJ về Pedra Branca và dải South Ledge với lập luận Pedra Branca và dải South Ledge "nằm trong lãnh hải của Malaysia, nên phải thuộc chủ quyền nước này chứ không phải Singapore" căn cứ vào Điều 60 Quy chế Tòa án quốc tế [14]. Chắc chắn, đề nghị xem xét lại và xin giải thích phán quyết của ICJ từ Malaysia sẽ ảnh hưởng tới "tiến trình thực hiện" sự đồng thuận của hai nước trong vấn đề chủ quyền của các đảo Pedra Branca, Middle Rocks và South Ledge.

Nhận thức rõ ràng các yêu cầu của Malaysia là xuất phát từ quyền của quốc gia và phù hợp với các quy định của pháp luật quốc tế về giải quyết tranh chấp, Singapore đã thể hiện thiện chí hợp tác với Malaysia nhằm giải quyết triệt để tranh chấp này. Sau khi nhận được thông báo từ Malaysia về việc nộp đơn yêu cầu xem xét lại phán quyết nói trên, Singapore đã nghiên 
cứu kỹ đơn và tài liệu của Malaysia, thành lập nhóm chuyên gia pháp lý (gồm có Bộ trưởng tư pháp Lucien Wong, Giáo sư S. Jayakumar, Giáo sư Tommy Koh và cựu Chánh án Chan Sat Keong) để xem xét yêu cầu của Malaysia [15]; lựa chọn Thẩm phán Gilbert Guillaume [16] tham gia vào quá trình giải quyết yêu cầu của Malaysia theo đúng Quy chế của Tòa. Singapore đã đệ trình Bản Ghi nhớ bằng văn bản về sự chấp nhận đơn đăng ký của Malaysia với ICJ vào ngày 24 tháng 5 năm 2017 theo đúng thời hạn và luôn sẵn sàng cho việc trình bày các lập luận theo đúng tiến độ mà ICJ đã ấn định cho thủ tục tố tụng. Với yêu cầu giải thích phán quyết từ Malaysia, mặc dù có sự phản đối nhưng Singapore luôn giữ vững cam kết giải quyết tất cả vấn đề theo đúng pháp luật quốc tế; đồng thời Singapore sẽ nộp Bản Ghi nhớ bằng văn bản của mình đối với vấn đề này trong một thời gian thích hợp [14].

Mặc dù có những sự kiện phát sinh ở thời kỳ hậu phán quyết 2008 về chủ quyền đối với Pedra Branca, nhưng với sự thiện chí, hợp tác đã được Malaysia và Singapore thể hiện trong suốt toàn bộ quá trình giải quyết tranh chấp cũng như thực hiện phán quyết 2008 sẽ cho cả khu vực và cộng đồng quốc tế tiếp tục có niềm tin về sự tôn trọng, tuân thủ pháp luật quốc tế, về sự tận tâm thiện chí và hợp tác của cả hai quốc gia trong việc giải quyết những tồn đọng của vụ việc này.

\section{Bài học kinh nghiệm cho Việt Nam}

Có thể nói thực tiễn giải quyết tranh chấp giữa Malaysia và Singapore về chủ quyền đối với đảo Pedra Branca và các đá là một bài học cho cả khu vực về giá trị của việc tôn trọng, tuân thủ các nguyên tắc cơ bản của pháp luật quốc tế, đó chính là những cam kết không sử dụng vũ lực hoặc đe dọa sử dụng vũ lực, tôn trọng độc lập, chủ quyền cũng như không can thiệp vào công việc nội bộ của nhau, hợp tác và cùng giải quyết tranh chấp bằng các biện pháp hòa bình và thực hiện các cam kết một cách thiện chí, tận tâm. Vận dụng kinh nghiệm của
Malaysia và Singapore trong việc áp dụng giá trị nội dung của các nguyên tắc này vào việc giải quyết tranh chấp ở Biển Đông có ý nghĩa nền tảng, là cơ sở pháp lý quan trọng cho Việt Nam trong việc bảo vệ chủ quyền, quyền chủ quyền, quyền tài phán của quốc gia, góp phần bảo vệ hòa bình, an ninh và tăng cường hợp tác hữu nghị với các quốc gia trong khu vực và trên thế giới. Cụ thể là:

Thư nhất, Việt Nam cần tiếp tục kiên trì thực hiện nghĩa vụ tìm kiếm phương thức giải quyết tranh chấp phù hợp, kiềm chế, quản lý tranh chấp để tranh chấp không bùng nổ thành xung đột bạo lực. Sử dụng vũ lực hay đe doạ sử dụng vũ lực để giải quyết các tranh chấp quốc tế cũng là trái với nghĩa vụ giải quyết các tranh chấp bằng các biện pháp hoà bình, trong đó có các tranh chấp về biển, đảo như đã được quy định trong Điều 2.3 Hiến chương Liên hợp quốc cũng như UNCLOS. Do vậy, Việt Nam cần kiên quyết dựa trên cơ sở pháp lý này yêu cầu Trung Quốc phải hành động một cách phù hợp với các tuyên bố chính thức cũng như các nghĩa vụ của quốc gia mình là tôn trọng pháp luật quốc tế; phải chấm dứt các hành vi sử dụng hoặc đe dọa sử dụng vũ lực trên biển, chấm dứt các hành vi làm phức tạp leo thang tranh chấp như quân sự hóa các đảo đang bị tranh chấp và thay đổi nguyên trạng ở Biển Đông; và giải quyết các tranh chấp trên Biển Đông bằng biện pháp hòa bình trên cơ sở tôn trọng độc lập, chủ quyền của quốc gia khác và tôn trọng pháp luật quốc tế, đóng góp tích cực vào việc duy trì hòa bình, ổn định ở khu vực cũng như trên thế giới.

Thư hai, giải quyết các tranh chấp thông qua cơ quan tài quốc tế phán là biện pháp hòa bình, minh bạch, giảm thiểu được nguy cơ xung đột, góp phần tạo dựng môi trường ổn định và duy trì quan hệ hợp tác, hữu nghị giữa các bên. Việt Nam cần chủ động trong việc sử dụng quyền lựa chọn và quyết định biện pháp giải quyết tranh chấp phù hợp với điều kiện hoàn cảnh và bản chất của tranh chấp và các quy định của pháp luật quốc tế; chủ động lựa chọn việc sử dụng các biện pháp tài phán và cơ quan tài phán quốc tế giải quyết tranh chấp làm cơ sở đề 
nghị với bên kia khi các biện pháp đàm phán hay phi tài phán khác không đạt được hiệu quả; chủ động đề xuất biện pháp giải quyết tranh chấp cho đến khi nhận được sự đồng ý của bên kia; công khai bày tỏ sẵn sàng giải quyết tranh chấp tại Biển Đông thông qua một cơ quan tài phán quốc tế. Dù Trung Quốc có đồng ý hay không thì điều này cũng ý nghĩa quan trọng trong việc thể hiện rõ Việt Nam là quốc gia có trách nhiệm trong cộng đồng quốc tế, sẵn sàng trở thành một bên trước Tòa để phân xử đúng sai.

Thư $b a$, để giữ vị thế bình đẳng và chủ động quá trình giải quyết tranh chấp, Việt Nam cần phải có những chuẩn bị chu đáo cho việc giải quyết tranh chấp và tranh tụng tại cơ quan tài phán quốc tế như: Tuyên bố chấp nhận thẩm quyền hoặc xây dựng thỏa thuận đặc biệt trao thẩm quyền giải quyết tranh chấp cho cơ quan quan tài mà mình lựa chọn; xác định chiến lược tranh tụng đúng hướng và xây dựng những lập luận pháp lý trên cơ sở những chứng cứ xác thực để khẳng định, bảo vệ yêu sách của mình; tìm hiểu, thu thập, nghiên cứu và đánh giá hết sức nghiêm túc các lập luận, các chứng cứ pháp lý và lịch sử mà đối phương sử dụng; đòi hỏi bên kia đưa ra chứng cứ cụ thể để chứng minh; chất vấn tính xác thực của chứng cứ, phản biện một cách hiệu quả các lập luận và chứng cứ của đối phương; tiếp tục ưu tiên đào tạo đội ngũ chuyên gia về luật quốc tế có trình độ chuyên môn, nghiệp vụ cao; chú trọng hơn nữa việc gửi người hoặc vận động gửi người tham gia vào các thể chế quốc tế, trong đó có các cơ quan tài phán quốc tế.

Thư tu, Việt Nam cần phối hợp và yêu cầu các bên liên quan cùng thực hiện nghĩa vụ hợp tác với nhau trong quá trình giải quyết tranh chấp, cùng nhau tìm kiếm các giải pháp hiệu quả trong việc giải quyết tranh chấp ngay từ khi tranh chấp phát sinh, cùng nhau quản lý, kiểm soát tranh chấp, không được có những hành vi làm leo thang tranh chấp, góp phần duy trì hòa bình, an ninh trong khu vực và quốc tế; cần vận động các bên liên quan cùng thực hiện các biện pháp tăng cường vai trò của ASEAN trong quản lý xung đột ở Biển Đông (như nâng cao nhận thức và trách nhiệm chính trị của mỗi thành viên ASEAN, xem xét lại phương thức làm việc, thay đổi những luật lệ cơ bản trong khâu ra quyết định của mình trước một số vấn đề chưa tìm được tiếng nói đồng nhất hoặc chủ động tạo dựng cơ chế đàm phán đa phương và tận dụng các diễn đàn quốc tế, các cơ chế an ninh khu vực); thúc đẩy việc xây dựng công cụ quản lý tranh chấp COC (văn kiện điều chỉnh hành vi của các bên trên Biển Đông); nỗ lực tìm kiếm các giải pháp tạm thời để cùng hợp tác quản lý tranh chấp trên tinh thần hiểu biết lẫn nhau nhằm khống chế nguy cơ xung đột, duy trì hòa bình, an ninh, thúc đẩy hợp tác xây dựng lòng tin và tạo môi trường thuận lợi cho việc tìm kiếm giải pháp cho các tranh chấp ở Biển Đông.

Thư năm, Việt Nam yêu cầu các bên liên quan trong tranh chấp phải tuân thủ, thực hiện đúng các cam kết quốc tế trong đó có các quy định về giải quyết tranh chấp trong các ĐUQT; không được cố tình viện dẫn, giải thích sai lệch các quy định trong các ĐUQT mà các quốc gia là thành viên như Hiến chương Liên hợp quốc , UNCLOS...

Tóm lại, quá trình giải quyết tranh chấp chủ quyền đối với Pedra Branca và các đá giữa Singapore và Malaysia đã mang đến những gợi mở pháp lý và những kinh nghiệm quý giá cho Việt Nam trong việc sử dụng các cơ quan tài phán và sử dụng những luận cứ pháp lý tại các cơ quan này trong tương lai. Tuy nhiên, để có thể thể hiện trách nhiệm của quốc gia đối với việc tuân thủ các nguyên tắc cơ bản của pháp luật quốc tế, sử dụng hiệu quả biện pháp quốc gia lựa chọn, đòi hỏi Việt Nam cần phải có những tính toán rất cụ thể, chi tiết và cẩn trọng về các nội dung pháp lý, đồng thời, cần dựa trên cơ sở đánh giá những vấn đề có liên quan khác như kinh tế, chính trị, ngoại giao, cục diện và diễn biến của tình hình thực tế để hạn chế thấp nhất những tổn thất kinh tế và các lĩnh vực khác, tranh thủ sự hậu thuẫn và ủng hộ mạnh mẽ của công luận quốc tế và của các cường quốc trên thế giới./. 


\section{Tài liệu tham khảo}

[1] Khoa Luật, ĐHQGHN (2014), Giáo trình Công pháp quốc tế, Nxb. ĐHQGHN.

[2] ICJ, Malaysia v. Singapore case, Judgment of 23 May 2008, http://www.icjcij.org/docket/files/130/14492.pdf.

[3] Robert Beckman and Clive Schofield (2009), "Moving Beyond Disputes Over Island Sovereignty: ICJ Decision Sets Stage for Maritime Boundary Delimitation in the Singapore Strait", Ocean Development \& International Law, Vol. 40, No. 1.

[4] S Jayakumar and Tommy Koh (2009), Pedra Branca: The Road to the World Court, Singapore National University Press.

[5] Liên hợp quốc (1945), Hiến chương.

[6] Liên hợp quốc (1970), Tuyên bố của Đại hội đồng về các nguyên tắc cơ bản của luật quốc tế điều chỉnh mối quan hệ hữu nghị, hợp tác giữa các quốc gia phù hợp với Hiến chương LHQ.

[7] Nguyễn Trường Giang (chủ biên), Vụ tranh chấp giữa Malaysia và Singapore về chủ quyền đối với đảo đá trắng, các đá "South Ledge" và "Middle Rocks" NXB. Chính trị Quốc gia, HN, 2012.

[8] Malaysia and Singapore, Special Agreement: Joint notification, dated 24 July 2003, addressed to the registrar of the court. http://www.icjcij.org/docket/files/130/1785.pdf

[9] Nguyễn Bá Diến (2013), Kinh nghiệm quốc tế về cơ chế giải quyết tranh chấp chủ quyền biển đảo, $\mathrm{Nxb}$. ĐHQGHN.

[10] Anna Louise Strachan, “Tòa án Công lý Quốc tế và tranh chấp lãnh thổ ở Đông Nam Á”, biên dịch: Phạm Văn Mỹ (Trích dẫn từ:tuanvietnam.net/2009-11-09-vai-tro-lon-h...aan-cong-ly-quoc-te).

[11] Singapore, Malaysia grapple with UN court decision, xem

Reuters, http://www.asiaone.com/News/Latest\%2 BNews/Asia/Story/A1Story20080526-67143.html và Strait Times, Pedra Branca: New joint panel formed,

http://www.asiaone.com/News/the\%2BStraits\% 2BTimes/Story/A1Story20080902-85422.html.

[12] Liên hợp quốc (1945), Quy chế Tòa án quốc tế.

[13] Ngọc Anh, (tổng hợp), Malaysia lật lại phán quyết về tranh chấp đảo với Singapore, http://dantri.com.vn/the-gioi/malaysia-lat-laiphan-quyet-ve-tranh-chap-dao-voi-singapore20170206112926008.htm, truy cập 6/2/2017.

[14] Ministry of foreign afairs Singapore, International Court of Justice - Case concerning sovereignty over Pedra Branca, Middle Rocks and South Ledge,

https://www.mfa.gov.sg/content/mfa/media_centr e/special_events/pedrabranca.html.

[15] MFA Spokesman's Comments on Malaysia's Application to Revise the International Court of Justice's Judgment on Sovereignty over Pedra Branca, Middle Rocks and South Ledge, 3 Feb 2017,

https://www.mfa.gov.sg/content/mfa/media_centre/p ress_room/pr/2017/201702/press_20170203.html.

[16] MFA Press Statement: Appointment of Singapore's Judge Ad Hoc for the Purposes of Malaysia's Application to Revise the International Court of Justice's Judgment on Sovereignty over Pedra Branca, Middle Rocks and South Ledge, 2 March 2017 , https://www.mfa.gov.sg/content/mfa/media_centre/p ress_room/pr/2017/201703/press_20170302.html. 


\title{
Application of the Basic Principles of International Law in the Case Concerning Sovereignty over Pedra Branca, Middle Rocks and South Ledge and Experience for Vietnam
}

\author{
Dao Thi Thu Huong \\ VNU School of Law, 144 Xuan Thuy, Cau Giay, Hanoi, Vietnam
}

\begin{abstract}
The basic principles of international law play a very important role in the resolution of international disputes in general and the settlement of international disputes over the sea and islands in particular, contributing to the protection of peace and international security. Based on the study of the dispute settlement process between Singapore and Malaysia concerning the sovereignty over Pedra Branca and Middle Rocks in the light of the basic principles of international law, the article provides an assessment of the respect and observance of international law by the related parties and experience for Vietnam in resolving disputes in the East Sea.
\end{abstract}

Keywords: ICJ, basic principles of international law; dispute of sovereignty over Pedra Branca, Malaysia v. Singapore case. 